\title{
A desesperança do jovem e o suicídio como solução
}

\author{
Maria Aparecida Penso* \\ \& Denise Pereira Alves de Sena**
}

Resumo: O suicídio é uma das três maiores causas de morte entre jovens de 15 a 29 anos no mundo. Compreender este fenômeno tem sido um grande desafio para todos. Por meio de uma revisão de literatura, este artigo pretendeu avaliar a interdependência entre as complexas relações sociais da contemporaneidade, sua influência na construção identitária dos jovens e a morte intencional como saída para dores emocionais. Por se tratar de um grave problema mundial de saúde pública, os números, mesmo subestimados, são assustadores. Para cada suicídio que acontece, houve entre 10 e 20 tentativas, e cada morte por suicídio afeta emocionalmente outras 60 pessoas próximas à vítima. Conclui-se que o suicídio é um fenômeno social que surge como um pedido de socorro dos jovens à família e à sociedade, uma vez que os eventos que ocorrem na exterioridade das frágeis relações sociais impactam diretamente na formação da subjetividade do ser.

Palavras-chave: Suicídio. Jovens. Aceleração social. Solidão. Vulnerabilidade.

\section{Young people's hopelessness and suicide as a solution}

Abstract: Suicide is one of the three leading causes of death among 15 to 29 year old in the world. Understanding this phenomenon has been a great challenge for everyone. Through a literature review, this article intended to evaluate the interdependence between the complex social relations of contemporaneity, its influence on the identity construction of young people and intentional death as an exit for emotional pain. Being a serious global public health problem the numbers, even underestimated, are frightening. For every suicide that happens there are 10 to 20 attempts, and each death by suicide emotionally affects other 60 people close to the victim. It is concluded that suicide is a social phenomenon that arises as a distress call from young people to the family and society, since the events that occur in the exteriority of fragile social relations directly impact the formation of the subjectivity of being.

Keywords: Suicide. Young adults. Social acceleration. Loneliness. Vulnerability.

\author{
* Maria Aparecida \\ Penso é psicóloga, \\ doutora em \\ psicologia pela \\ Universidade de \\ Brasília, professora \\ do Programa de \\ Pós-Graduação \\ em Psicologia da \\ Universidade Católica \\ de Brasília, Distrito \\ Federal, Brasil. \\ Orcid: 0000- \\ 0003-1200-8088. \\ $<$ mariaaparecida \\ penso@gmail.com>.
** Denise Pereira Alves de Sena é psicóloga clínica e psicanalista, doutoranda em psicologia do Programa de Pós-Graduação em Psicologia da Universidade Católica de Brasília, Distrito Federal, Brasil. Orcid: 0000-0002- 7750-2928. <dsena.psi@gmail. coms.




\section{Introdução}

E

ste artigo tem como tema as complexas relações entre as questões sociais da contemporaneidade e o suicídio de jovens. A morte é um marcador social do qual nenhum humano será poupado, desenhando-se mesmo como a única certeza que temos. O suicídio é um fenômeno social mundial e um problema de saúde pública observado desde a Antiguidade, provocando sofrimento naqueles que conviviam com as vítimas (Brasil, 2017). Segundo a Organização Mundial da Saúde (OMS, 2002), o suicídio consiste em um ato intencional para acabar com a própria vida. Atualmente, a cada 40 segundos uma pessoa comete suicídio no mundo. Para discutir este tema, assume-se aqui a existência de um sujeito social que emerge da unidade mantida na instância do imaginário e do simbólico (Barus-Michel, 2004). Baseado nas concepções de Jacqueline Barus-Michel, compreende-se o sujeito como uma construção imaginária e uma representação mais ou menos elaborada daquilo que deve satisfazer as aspirações supostamente comuns e que as expressa. Deste modo, o artigo pretende refletir, a partir de uma revisão de literatura, sobre como o atual contexto no qual os jovens estão inseridos influencia sua construção identitária, levando à tomada de decisões que implicam na sua saúde mental e até mesmo na retirada intencional da própria vida, ou seja, no suicídio.

\section{Saúde mental e suicídio: dados epidemiológicos e definições}

A palavra suicídio - criada em 1737, por Desfontaines com origem no latim: sui (si mesmo) e cæderes (ação de matar) - aponta para a necessidade de se buscar a morte como refúgio para o sofrimento que se torna insuportável, ou seja, não é uma ato de coragem e nem de covardia, é um ato de desespero. Por se tratar de uma ação voluntária e intencional, que objetiva cessar a vida do praticante após certo grau de reflexão, planejamento e ação, parte do ponto de vista que a morte significa o fim de tudo (Assumpção Jr. 2018; Solomon, 2018).

A concretização do suicídio pode ser por meios letais - como o uso de armas brancas e de fogo, enforcamento (práticas mais comuns entre os homens) - ou com a ingestão de fármacos ou de substâncias letais (práticas mais comuns entre as muIheres). Também pode ocorrer por formas disfarçadas de atentar contra a própria vida, como o uso abusivo de álcool e drogas, a prática de esportes ou atividades de lazer que coloquem a vida em risco, a falta de cuidados para com a própria saúde ou ainda uma vida sexual promiscua (Ribeiro \& Moreira, 2018). 
O sociólogo francês Émile Durkheim publicou, em 1897, a obra Le suicide, que foi única em sua época, na qual relaciona o evento suicídio a causas sociais. Segundo Durkheim o suicídio seria

todo o caso de morte que resulta, direta ou indiretamente, de um ato, positivo ou negativo, executado pela própria vítima, e que ela sabia que deveria produzir esse resultado (Durkheim, 2014: 25).

Durkheim afirma que cada sociedade está predisposta a fornecer um contingente determinado para mortes voluntárias, interessando para a sociologia a análise do processo social do suicídio, pois cada sociedade, em cada momento da história, oferece uma atitude social em relação ao autoextermínio.

O autor classifica o suicídio, conforme o funcionamento social, em três tipos, a saber: anômico, egoísta e altruísta (Durkheim, 2014). No anômico, a anarquia social está presente, não existem regras ou coesão social, as instituições como governo, família e sociedade estão desreguladas, desajustadas e corrompidas, ou seja, não há motivo para o sujeito agir de forma ética, nem mesmo consigo próprio. Este tipo de suicídio poderia ocorrer em crises financeiras, por exemplo, onde certos indivíduos ficam em situação inferior àquela ocupada anteriormente. Assim a perda de poder aquisitivo poderia aumentar os índices de suicídio. Cabe destacar, que, para o autor, esse tipo de suicídio seria mais comum em países ricos, pois os pobres têm mais habilidade para lidar com situações de anomia social. Já no egoísta haveria a prevalência do ego individual ao social, onde o sujeito estaria muito empenhado em realizar desejos materiais, a individualização é extrema e as relações entre o sujeito e a sociedade são superficiais, provocando a falta de sentido no viver e melancolia. No altruísta, haveria a prevalência do social, quando os interesses da maioria fossem dominantes diante do interesse individual, a exemplo dos pilotos japoneses kamikazes.

Dados do relatório da Organização Mundial de Saúde apontam que, em 2014, 420 mil pessoas morreram vítimas de guerra, enquanto 850 mil pessoas foram vítimas de autoextermínio, configurando-se como um problema mundial de saúde pública, constituindo uma das dez maiores causas de morte em todos os países, e uma das três maiores causas de morte entre os jovens de 15 a 29 anos no mundo (OMS, 2018). Esta Folha informativa sobre suicídio da OMS demonstra ainda que 800 mil pessoas morrem por suicídio todos os anos, sendo a segunda principal causa de morte entre esses mesmos jovens com idade entre 15 e 29 anos, perdendo apenas para os atos de violência. O relatório destacou ainda a estreita relação entre suicídio e distúrbios mentais (em particular a depressão e o alcoolismo). Contudo, 
momentos de crise (financeira, relacional e de saúde) e experiências associadas a abusos, violências, desastres, experiências de grupos vulneráveis que sofrem discriminação e enfrentamento de conflitos ajudam a aumentar essa triste estatística.

No relatório da OMS, o Brasil ocupa a oitava posição em números totais de suicídios. Os países que apresentam os maiores índices de suicídios estão apresentados na Tabela 1.

TABELA 1

PAÍSES QUE APRESENTAM

O MAIOR ÍNDICE DE SUICÍDIOS (MIL)

\begin{tabular}{|l|c|}
\multicolumn{1}{|c|}{ País } & $\begin{array}{c}\text { N de óbitos/ } \\
\text { ano (mil) }\end{array}$ \\
\hline Índia & 258,0 \\
\hline China & 120,7 \\
\hline Estados Unidos & 43,0 \\
\hline Rússia & 31,0 \\
\hline Japão & 29,0 \\
\hline Paquistão & 13,0 \\
\hline Fonte: OMS, 2014.
\end{tabular}

Contudo, é sabido que os registros das tentativas concluídas não são fidedignos à realidade, e as tentativas sequer são contabilizadas, o que dificulta a compilação exata das estatísticas (Botega, 2010).

Apesar de os dados numéricos relacionados ao suicídio serem subestimados, a estatística é de que para cada suicídio que acontece, houve entre 10 e 20 tentativas. Quando a pessoa consegue consumar sua intenção, o fato afeta emocionalmente outras 60 pessoas próximas. Além disso, entre 40 e $60 \%$ das pessoas que cometeram suicídio consultaram algum serviço médico no mês anterior ao ato, portanto, mesmo com os registros aquém da realidade, os números evidenciam a magnitude desse problema de saúde pública (Gonçalves, Freitas \& Sequeira, 2011; Cantão; Botti, 2016). O maior índice de suicídio está entre os homens (79\%), todavia, a maior incidência de tentativas de suicídio está entre as mulheres (Brasil, 2018).

Ainda sobre a limitação do alcance dos dados sobre suicídio, é preciso lembrar que existem muitos suicídios registrados de maneira diferente nos prontuários dos hospitais, como homicídio ou acidente, por exemplo, em razão da omissão social com relação ao suicídio (Angerami, 2013). Nesse sentido, Valdemar Augusto Angerami aponta que, em casos de mortes por causas externas, é comum que seja registrado no atestado de óbito a natureza da lesão que levou à morte, sem fazer referência 
às circunstâncias que a originou. Quanto às tentativas, o autor afirma que é impossível identificar a quantidade exata que ocorre cotidianamente, seja pelo fato de o paciente apresentar dados falsos de identificação, seja porque se impõe uma causalidade acidental ao comportamento da tentativa de suicídio.

Portanto, deve-se pensar a magnitude desta questão considerando que o sofrimento que a gera não é apenas individual, mas, principalmente, social. Devemos buscar entender que mensagem social os jovens estão nos passando quando cometem tais atos. Que fraturas existem no seu contexto para que não se consiga sobrepor suportes identitários suficientemente fortes para conter esses jovens, não os deixando, com isso, desamparados?

\section{A identidade como construção familiar e social}

Ao buscar uma reflexão sobre os questionamentos colocados na seção anterior, procuraremos aqui discutir os suportes identitários existentes para estes jovens na atualidade. Assume-se a perspectiva que o sujeito se constrói no encontro do indivíduo com o contexto social em um processo dinâmico de afiliação psicossociopolítica. Assim, quando o sujeito se confronta com acontecimentos que ocorrem na exterioridade das relações sociais, há também este confronto no domínio da subjetividade, já que os comportamentos humanos têm suas raízes tanto no inconsciente como no processo de socialização (Gaulejac, 2009). Assim, o sujeito elabora interpretações sobre si mesmo, o que, para Vincent de Gaulejac (2009), é fundamental para a construção de sua identidade pois é justamente na capacidade de se imaginar outra vida que se extrai energia para construir a de hoje. Nesta perspectiva, o indivíduo é produto e agente de sua própria história (Rhéaume, 2009).

O primeiro grupo social do sujeito é a família, onde são estabelecidas as primeiras relações afetivas, bem como as principais identificações, fazendo dela um contexto fundamental de suporte e identificações. Neste sentido, a qualidade dos vínculos construídos por este sujeito e seu sistema familiar é fundamental para o estabelecimento do sentimento de pertencimento e posterior separação, possibilitando a construção identitária (Minuchin, 1982; Minuchin, Lee \& Simon, 2008).

Outros grupos sociais também são espaços de identificação e construção identitária do sujeito. Podemos citar a escola, o trabalho e o grupo de pares. A escola, por ser obrigatória para todos, depois da família, é um contexto possível de identificações 
e suporte identitário que permeará a vida de todos, representando a oportunidade do encontro de um lugar de pertencimento e inserção social (Penso, et alii, 2012). Deste modo, caberia à escola, além de desenvolver processos de ensino/aprendizagem, contribuir para aspectos como percepção e construção da cidadania, convivência social e, principalmente, para o estabelecimento de relações intersubjetivas favoráveis à construção de resposta social aos desafios colocados pela sociedade. No entanto, a escola se tornou um campo de injunções paradoxais entre competir e cooperar, ser autônomo e repetir o que os professores acham adequado, existir e ser invisível. O que deveria ser um espaço de pertencimento, tem-se tornado um contexto de sofrimento, indiferença, e ausência ou fragilidade dos vínculos. Essas situações têm levado ao adoecimento e ao abandono da escola de muitos estudantes. Observa-se que a escola não insiste para que os adolescentes e os jovens lá estejam.

O trabalho é outro importante suporte identitário, sendo uma via para a aquisição de bens de consumo e sentido de pertencimento, numa sociedade que prioriza o ter em lugar do ser. Na sociedade regida pelo capitalismo, onde o modelo dominante é o econômico, estão excluídos aqueles que não podem consumir (os pobres) ou não podem produzir (os desempregados) (Xiberrás, 1989). No entanto, como aponta Norma Missae Takeuti (2002), numa sociedade de consumo, os adolescentes, mesmo que ocupem lugares rejeitados, estão submetidos às solicitações consumistas e buscam entrar no frenético movimento de consumo que os coloca no status de cidadãos. O trabalho, portanto, é um eixo de inserção versus não inserção e de construção identitária, pois oferece sustento econômico, identidade pessoal e espaço de vinculação afetiva e socialização. Por outro lado, muitas vezes o contexto de vulnerabilidade não permite o "tempo para ser jovem", pois é preciso assumir a responsabilidade do trabalho em uma época em que seria importante um descompromisso com o processo produtivo para possibilitar a preparação para a idade adulta (Carreteiro, 2011).

Não ter trabalho pode despertar um sentimento de vergonha e inutilidade, configurando uma forma de desfiliação de diversos contextos, acentuando o individualismo para aqueles que possuem suportes materiais e econômicos, e introduzindo maior exclusão juntos aos indivíduos que não dispõem desses suportes, os chamados "indivíduos por falta" (Castel, 1998). Essas novas formas de desfiliação têm gerado o imaginário da inutilidade, capaz de fazer emergir seres sem qualquer qualidade para a sociedade, totalmente descartáveis (Carreteiro, 2003).

Os grupos de pares constituem-se em importante contexto de inserção para o jovem, sendo fundamental como suporte identitário, pois a vivência grupal é estru- 
turante na vida do sujeito (Barus-Michel, 2004). São lugares privilegiados de formação dos "envelopes identitários" e de constituição de espaço intermediário de passagem entre a realidade psíquica e o mundo exterior (Carreteiro, 1993). Nesses grupos, o sujeito - principalmente os adolescentes e jovens - experimenta oportunidades de relacionamentos amparados no respeito e na confiança mútuos, permitindo a troca de experiências e expectativas de vida, e o ensaio de alguns arranjos de enfrentamento de dificuldades e de busca de suportes identitários. O grupo de pares, na adolescência, possibilita a vivência do tempo da margem (um tempo de experimentações, à margem de escolhas ainda não realizadas), de uma nova gestação, permitindo identificações múltiplas e efêmeras, facilitando a construção de estilos de sociabilidade e solidariedade, o que alivia a angústia adiante da problemática identitária (Sélosse, 1997).

Na adolescência e na juventude, o grupo é o espaço para a vivência da curtição e da transgressão, possibilitando ao jovem testar a sua capacidade de circular à margem, sem romper com o seu contexto social. Essa é uma experiência muito importante, pois assegura ao jovem controlar os seus impulsos agressivos e realizar o seu desejo de estar entre iguais. Maria Aparecida Penso e colaboradoras (2012) - em sua pesquisa com adolescentes infratores - apontam que nas histórias construídas por eles, os amigos estão sempre muito presentes e fazendo parte do seu cotidiano, quase sempre associados a festas, ao futebol e ao lazer ou ajudando em momentos difíceis. No entanto, também apontaram que, muitas vezes, foram os amigos que os colocaram em situações complicadas e de risco. Assim, as autoras concluem que o grupo de pares que deveria desempenhar o papel de possibilitar a vivência do tempo da experimentação é visto como podendo ser ameaçador à integridade do adolescente, gerando um paradoxo entre isolar-se do grupo de pares para não se envolver em situações de risco, perdendo um suporte identitário muito importante, ou continuar no grupo arriscando expor-se a qualquer momento em situações de vulnerabilidade.

Em um momento de grandes transformações na sociedade e na família, de relações fragilizadas e de desigualdades marcadas pelo gênero, pela raça e pela idade, estes suportes identitários, mesmo se continuam fundamentais, muitas vezes funcionam de forma ineficiente, oferecendo mais riscos que oportunidades ao jovem. Cabe, portanto, refletir sobre que sociedade é esta na qual estes jovens estão vivendo e como as experimentações, necessárias na juventude, são percebidas pelo social. 


\section{As transformações nas relações e seu impacto na subjetividade dos jovens: qual o sentido da vida?}

Numa sociedade onde tudo muda o tempo todo, torna-se importante refletir sobre como ficam os suportes identitários nomeados na seção anterior. Como aponta Zygmunt Bauman (2001), vivemos um tempo de liquidez, ou seja, ele jamais se imobiliza, muito menos conserva sua forma por muito tempo, provocando um fenômeno que combina a falta de garantias (de posição, títulos e sobrevivência), as incertezas (em relação à própria continuidade e estabilidade futura) e as inseguranças (do corpo, do Eu e de suas posses, comunidade, vizinhança).

Ao considerar o sujeito como assujeitado às determinações psíquicas e sociais, este momento de aceleração e liquidez deverá adaptar-se para construir seu processo de emancipação e autonomia em uma relação dialética entre o assujeitamento e a subjetivação (Barus-Michel, 2004; Gaulejac, 2005; 2009). Significa dizer que é entre duas forças - uma advinda da socialização e do processo de produção social dos indivíduos, outra da tomada de consciência de si mesmo - que o indivíduo busca construir sua singularidade, sua capacidade de pensar, de se afirmar e de assumir os seus próprios desejos (Gaulejac, 2009; Isaac Silva, 2015).

Ao considerar o pressuposto de que o processo de constituição e individuação do sujeito tem íntima relação com a interação estabelecida socialmente, ou seja, ao manter relações com o mundo social, o sujeito adquire as compreensões necessárias para moldá-lo e engendrá-lo tal como é (Morin, 2007), cabe perguntar, neste modelo social líquido e acelerado, qual a qualidade das trocas? Claudine Haroche (2015) problematiza as atuais circunstâncias do desenvolvimento da vida mental que tem sido perturbada pela aceleração, pelo imediatismo, pela instantaneidade e pela tecnologia. Nesta mesma linha de raciocínio, Bauman (2005) afirma que a tecnologia que facilita a comunicação é a mesma que afasta as pessoas, atrapaIhando a vinculação, a troca de olhares e o aprendizado que as relações interpessoais são capazes de proporcionar.

A manutenção da sociedade de consumo impõe o sucesso profissional baseado no esgotamento individual, onde o ter se sobressai ao ser, e na exigência de investimento ilimitado em si mesmo, sendo necessário ter tudo e ser muito o tempo todo. Por outro lado, no auge da era da liquidez, o ser humano se despersonaliza e adquire o estatuto de coisa a ser consumida para, em seguida, ser descartada, tornando as relações substituíveis diante da menor demonstração de dificuldade. 
São relações utilitaristas. As trocas amorosas são realizadas pela tela, tornando os relacionamentos assépticos e descartáveis, não exigindo compromisso efetivo de nenhuma das partes (Bauman, 2005). No entanto, é próprio do ser humano a necessidade de reconhecimento e aceitação pelo outro. Surge então um dos grandes paradoxos da pós-modernidade: viver relações descartáveis, desejando ser único e reconhecido.

Diante de um cenário de aceleração e liquidez, Valdemar Angerami-Camon (2008) afirma que as mudanças sociais, a evolução da sociedade, os benefícios, as oportunidades, as novas formas de vinculação e deveres e obrigações têm provocado sofrimento psíquico em todos, especialmente nos jovens que, incapazes de lidar com tais desafios, encontram na morte uma forma de "fuga" dessa realidade. A juventude - etapa que compreende dos 15 aos 29 anos - é um período da vida permeado por grandes mudanças biológicas, psicológicas, relacionais e sociais. Neste período, os jovens são tratados como crianças em um momento, e no momento seguinte como adultos, sem que tenham disposto do "tempo" necessário para amadurecer, o que gera muita ansiedade (Araújo, Vieira \& Coutinho, 2010; Sena \& Penso, 2019). Por outro lado, o que vem dos jovens não é valorizado pelos adultos, gerando grande mal-estar nessas relações geracionais.

Numa sociedade baseada no consumo, com relações frágeis, os jovens encontram-se presos em processos desqualificadores e paralisantes, em elevadas exigências de performance e poucas expectativas para o futuro. Assim são levados a "construir[em] suas biografias em um território que não oferece garantias sobre o futuro" (Souza \& Castro, 2014: 173). Francisco Assumpção Júnior (2018) destaca que as frágeis relações familiares e, consequentemente, sociais do mundo pós-moderno exigem de todos os jovens, independentemente da classe social à qual pertencem, uma capacidade para lidar com frustrações, cobranças e planos futuros para os quais eles não foram preparados.

Os jovens que vivem em contextos de pobreza e vulnerabilidade - caracterizados por Castel (1998) como "indivíduos por falta" - veem-se aprisionados em situações vinculadas à falta de oportunidades e carências, fazendo com que seus sonhos sejam boicotados ou adormecidos e seus planos pessoais sem possibilidades de realização. Oriundos de contextos familiares e institucionais (escola, trabalho) que não possibilitam contextos de pertencimento adequados, o grupo parece ser a mais forte alternativa de construção identitária, pois fornece a ilusão de que encontraram o seu espaço. Impedidos de ter acesso à ordem social pela família, procuram fazê-lo pelo grupo (Sélosse, 1997). Para Jacques Sélosse, neste contexto de desfiliação em que o tecido relacional é restrito e os grupos dos quais participam - que deveriam 
funcionar como espaços de pertencimento, na maioria das vezes - são marcados por rupturas abruptas e situações de grande sofrimento.

Por outro lado, os jovens provenientes das classes média e alta encontram-se presos a grandes exigências de sucesso profissional e pessoal. Precisam ser brilhantes e ultraprodutivos. Ascensão e sucesso profissional é um tema constante na vida destes jovens, e o diploma universitário uma condição para a vida profissional. A exigência social e familiar da burguesia para com os jovens começa no período escolar, passa pela escolha da graduação, o vestibular, a conclusão do curso e a inserção exitosa no mercado de trabalho. Essa dinâmica traz para a realidade desses jovens problemas de memória, cansaço constante, irritabilidade, insegurança, cobranças, estresse, ansiedade, depressão, sintomas físicos como queimação gástrica, hipertensão arterial, problemas dermatológicos, diminuição da libido, dentre outros (Pereira, 2014).

Paradoxalmente, a relação entre a alta qualificação e a boa colocação no mercado de trabalho nem sempre se confirma, uma vez que existem mais jovens com alto nível de formação do que postos de trabalho. Marina Coelho de Souza e Lúcia Rabello de Castro (2014) concluem que o momento contemporâneo de imprevisibilidade parece contagiar os jovens no momento de construção do futuro profissional, fazendo com que não apresentem preocupações com o planejamento do amanhã. Isso significa que o não planejar se constitui como modo de se relacionar com as incertezas, com as vivências episódicas e fragmentárias, levando à valorização da liberdade individual.

Alceu Casseb (2007) defende que a escolha profissional contribui para a compreensão do mundo interno do jovem estudante, que vive simultaneamente o processo de identificação e diferenciação dos pais, necessitando de uma "dose" de transgressão. Como transgredir se os jovens estão adoecidos e fragilizados? Aos pais e à sociedade cabe oferecer espaço emocional para que essa transgressão seja vivida, amparando a oscilação entre o desejo de autonomia e o ódio à dependência, à falta de experiência e à sensação de solidão. Caso essas contradições não sejam experienciadas na adolescência, podem se tornar transgressões ocultas, o que leva a uma organização adolescente na vida adulta sujeita a depressão e a picos de ansiedade.

Além da cobrança social e familiar, ao jovem também cabe lidar com um mercado de trabalho diferente daquele que seus pais conheceram. Bauman (2001) afirma que a dependência do capital e do trabalho na sociedade passada equivalia aos casamentos à moda antiga, ou seja, não era possível desfazê-los, pois eram para sempre. Contudo, na sociedade líquida moderna, essa relação tornou-se mais des- 
cartável. Não há mais estabilidade nem garantias, o trabalho não se materializa enquanto vocação para a vida toda, pois aquele trabalho que mantinha uma dependência intima com o capital agora se relaciona intimamente com a lógica de consumo. Richard Sennett (2002) destaca que os jovens americanos esperam mudar de emprego pelo menos 11 vezes na vida e, ainda, mudar de aptidão básica ao longo da vida pelo menos três vezes.

Importante ressaltar que, independentemente da classe social à qual pertencem, os jovens estão vivendo em um contexto onde os vínculos são frágeis, as trocas provisórias e as relações utilitaristas. São jovens sem utilidade e muitas vezes sem futuro.

\section{O que pode acontecer}

quando a vida perde o sentido:

drogas, depressão, suicídio

Afora as questões sociais levantadas acima, o sujeito, em sua juventude, depara-se com o fim do "roteiro programado de vida", onde as incertezas sobre o próximo passo a ser dado tornam-se constantes e o colocam em xeque, fazendo com que questione o próprio sentido de sua existência: o fim do ensino médio, a escolha da carreira profissional, o ingresso na faculdade, o início e o desenvolvimento da vida social, afetiva e relacional, a individuação e a diferenciação enquanto sujeito separado da família, definição × escolha da vida sexual, início da vida profissional, o pagar as contas, entre outros. Portanto é um momento crucial do desenvolvimento em que o sujeito entrará em contato com os próprios recursos para lidar com frustrações, decepções, conquistas, incertezas e escolhas. Nesses momentos, adoecimentos como a depressão e a ansiedade podem se desenvolver, o uso de álcool e outras drogas podem "ajudar" e fazer pertencer (Medina, Pérez \& Mejía, 2008; Botega et alii, 2009).

Também pode emergir o desejo de não estar mais neste mundo, de morrer. Assim, quando não se encontra mais sentido na vida, o seu fim pode ser uma saída. Como afirma Gonçalves (2018), em momentos de desespero, ao enfrentar o dilema entre existir ou não existir, muitas pessoas decidem pela morte. Fatores como desordens mentais, históricos familiares de suicídio e o bullying, atualmente evidenciado nas escolas, acumulam-se como causas para o aumento do suicídio (Faro \& Santos, 2018).

As grandes mudanças emocionais, sociais, familiares, físicas, sexuais, econômicas e relacionais podem ser elencadas como preditores nos casos de suicídio entre jovens (Teixeira Filho \& Rondini, 2012; Cantão \& Botti, 2015). Elsa Viviana Barrón e Claudia Sandra Krmpotic (2016), por sua vez, apontam que existem dois grupos principais 
de risco para o suicídio: a predisposição (que incluem famílias instáveis, abandonadoras, rígidas, ausentes, famílias que não se importam, doenças mentais e ambiente educacional inadequado) e os gatilhos, sendo esses últimos sempre sociais.

Barrón e Krmpotic (2016) destacam, ademais, que quando um jovem põe fim à própria vida deseja, em verdade, deixar de sofrer e não morrer. Neste sentido, o suicídio pretende acabar com a dor insuportável e nessa tentativa o sujeito termina com a própria existência. Entre os pacientes que comentem suicídio, cerca de $90 \%$ dos casos, nos países ocidentais, sofrem ao menos de um transtorno psiquiátrico significativo (Kutcher \& Chehil, 2007). Stanley Kutcher e Sonia Chehil destacam, ainda, que embora seja provável que haja variações nesse cenário em diversos países e culturas, a íntima relação entre doença mental e suicídio precisa ser pesquisada.

Com relação aos adoecimentos mentais, a depressão grave é a causa mais relacionada à ideação suicida, especialmente entre os jovens, estando diretamente relacionada à forma como se constrói a subjetividade do ser, ao enfrentamento de experiências como violência sexual, dificuldades de vincular-se com outras pessoas, abuso de álcool e outras drogas, além do investimento inconsciente em atividades que colocam a vida em risco (Medina, Pérez \& Mejía, 2008; Toro-Tobar, Grajales-Giraldo \& Sarmiento-López, 2016).

Na revisão de literatura realizada por Eduardo Chachamovich, Sabrina Stefanello, Neury Botega e Gustavo Turecki (2009) demonstrou-se que as características clínicas da depressão - como a impulsividade e a agressividade - são potencializadoras de atos suicidas em menores de 30 anos. Uma meta-análise sobre diagnósticos psiquiátricos e suicídio indicou que $87,3 \%$ dos sujeitos apresentavam algum diagnóstico psiquiátrico previamente ao suicídio. Em geral, 43,2\% apresentavam transtorno de humor, 25,7\% transtorno por uso de substâncias diversas, 16,2\% diagnóstico de transtorno de personalidade e 9,2\% transtornos psicóticos. Ao analisar o pico de suicídios alinhados com episódios depressivos, os autores apresentam uma estatística mais assustadora ainda: $74,4 \%$ dos suicídios estavam associados ao primeiro episódio de depressão grave, 18,8\% relacionavam-se ao segundo episódio e 6,5\% associavam-se a mais de dois episódios.

Já Simone Santos, Giovanni Lovisi, Letícia Legay e Lúcia Abelha (2009) investigaram as tentativas de suicídio em um hospital de emergência no Rio de Janeiro, no período de 2006-2007. Foram analisados 96 casos por meio do instrumento Composite Internacional Development Interview, sendo a sua maioria composta por mulheres jovens, com idades entre 14 e 24 anos, de baixa escolaridade que ingeriram psicoativos em grande quantidade. Os episódios depressivos estavam presentes 
em 38,9\% dos casos, seguido por dependência de substância psicoativas (21,9\%), transtorno de estresse pós-traumático $(20,8 \%)$, dependência de álcool $(17,7 \%)$ e esquizofrenia (15,6\%), ou seja, $71,9 \%$ dos achados dialogam com questões relacionadas a transtornos mentais.

Liliane Ores, Luciana Quevedo, Karen Jansen, Adriana Carvalho, Taiane Cardoso, Luciano Mattos Souza, Ricardo Pinheiro e Ricardo Azevedo da Silva (2012), por sua vez, realizaram estudo descritivo com 1.560 jovens entre 18 e 24 anos, na cidade de Pelotas, Rio Grande do Sul, por meio de entrevistas e testes psicológicos, e mapearam a ocorrência de bipolaridade e ansiedade entre aqueles que apresentavam risco de suicídio. Os pesquisadores identificaram que $8,7 \%$ dos entrevistados apresentaram risco de suicídio, sendo que 53,3\% tinham sintomas de depressão grave, $29,6 \%$ sintomas de bipolaridade e $17,03 \%$ sintomas de ansiedade. Entre aqueles que apresentaram risco de suicídio, foi possível mapear as atitudes arriscadas contra a própria vida: não utilizar cinto de segurança $(9,8 \%)$, não utilizar capacete ao andar de moto ou bicicleta (8,9\%), ultrapassar o sinal vermelho $(6,3 \%)$, dirigir bêbado ou andar de carona com motorista bêbado (6,9\%). Ainda entre os mesmos pesquisados, 18,4\% ingeriram bebida alcoólica e sofreram acidentes que os obrigou a ir ao hospital.

O consumo e abuso de drogas, entre jovens, está entre os fatores que aumentam o risco de comportamento suicida. Os usuários de drogas têm suas tentativas de suicídio variando entre $25 \%$ a $50 \%$, sendo associadas a quadros depressivos, impulsividade, agressividade e problemas de autoestima (González-Forteza, Juárez López, Montejo León, Oseguera Díaz, Wagner Echeagaray, Jiménez Tapia, 2015). Para Penso e Conceição (2018), o uso abusivo de drogas pode se configurar como um padrão de enfrentamento autodestrutivo diante dos eventos da vida, na impossibilidade de enxergar outras formas de resolução dos dilemas da existência.

As informações acima apresentadas nos levam a concluir que o suicídio não é um ato isolado, está relacionado a uma condição de sofrimento e adoecimento do sujeito que, impossibilitado de resolver tal sofrimento por outras vias, vê na morte sua única solução.

\section{Ações de enfrentamento do suicídio no Brasil}

O suicídio é uma preocupação mundial. No Brasil, as ações do âmbito governamental tiveram seu início em 2006, por meio da Portaria n. ․ 1.876, que instituiu as diretrizes nacionais para prevenção do suicídio, e lançou o manual para profissionais 
da saúde (Brasil, 2006). Em 2011, a Portaria n.o 3088 instituiu a Rede de Atenção Psicossocial (Raps) para pessoas com sofrimento ou transtorno mental, objetivando seu atendimento desde a atenção básica até a atenção hospitalar e serviços de urgência e emergência sob a coordenação dos centros de atenção psicossocial (Caps) (Brasil, 2011). A criação desta rede foi fundamental, retirou o foco das ações de saúde mental apenas da atenção especializada e as colocou em todos os níveis de atendimento. No bojo desta atenção, estão todas as questões relacionadas à depressão e à ansiedade, que são fatores de risco para o suicídio.

No entanto, a despeito do aumento do número de casos de tentativas de suicídio e de suicídios consumados, somente em 2014, a Portaria n.o 1271 incluiu na Lista Nacional de Notificação Compulsória de doenças, agravos e eventos de saúde pública nos serviços de saúde públicos e privados as tentativas de suicídio e o suicídio (Brasil, 2014). Em 2017, o Ministério da Saúde lançou a agenda de ações estratégicas para a vigilância e prevenção do suicídio e promoção da saúde no Brasil 2017-2020 (Brasil, 2017). Finalmente, em abril e 2019, foi promulgada Lei 13.819, que impõe a participação da sociedade civil e de instituições privadas de saúde e educação na promoção da saúde mental para prevenção de automutilação e suicídio, construindo a compreensão de que o suicídio precisa de ações conjuntas entre o governo e a sociedade.

Todas estas ações governamentais são de extrema importância, pois, como coloca Andrew Solomon (2018) no campo do suicídio, retirar sua invisibilidade, trazendo-o para a área pública, sugere o desenvolvimento de novas perspectivas sob o aspecto do acolhimento, da compreensão, do cuidado e da valorização da vida.

Para dar visibilidade ao fenômeno, em 2003 o dia 10 de setembro foi instituído pela Organização Mundial da Saúde (OMS) como o Dia Mundial da Prevenção do Suicídio. A cor amarela foi escolhida para representar a campanha, em razão da experiência vivida pela família Emme. Em 1994, Mike Emme, de 17 anos, matou-se. Mike era conhecido por sua personalidade caridosa e por sua habilidade mecânica. Restaurou um Mustang 1968 e o pintou de amarelo. Mike amava aquele carro e por causa dele começou a ser conhecido como "Mustang Mike". No dia do funeral, os amigos colocaram uma cesta com fitas amarelas disponíveis para quem quisesse usá-las e possuíam uma mensagem "se você precisar, peça ajuda". Este ato provocou forte repercussão e em poucas semanas o tema suicídio apareceu em diferentes espaços e muitos jovens pediram ajuda. A fita amarela foi escolhida como símbolo do programa que incentiva aqueles que têm pensamentos suicidas a buscar ajuda. 
No Brasil, o Setembro Amarelo foi uma campanha de prevenção ao suicídio, iniciada em 2015, tendo sido uma iniciativa do Centro de Valorização da Vida (CVV), do Conselho Federal de Medicina (CFM) e da Associação Brasileira de Psiquiatria (ABP). O Brasil manteve o mês de setembro e a ideia foi a de promover eventos que abrissem espaço para debates sobre suicídio e divulgassem o tema alertando a população sobre a importância de sua discussão. Durante o mês da campanha, costuma-se iluminar locais públicos com a cor amarela e incentivar a promoção de palestras, eventos, programas de rádio e entrevistas sobre o suicídio.

No ano 2000, a OMS (2000) também elaborou uma cartilha para orientar profissionais da mídia na abordagem do tema suicídio. As orientações seguem o padrão de noticiar de forma responsável com ações como: trabalhar em parceria com autoridades da área as saúde, usar o termo "suicídio consumado" e não "suicídio bem-sucedido", fornecer informações de locais e números de telefone de pessoas capacitadas para ajudar a quem precise, não publicar fotos, cartas de despedidas, nem informar o método usado, dentre outras disposições. No Brasil, o Ministério da Saúde (Brasil, 2017), em seu plano de prevenção do suicídio, também faz orientações quanto à forma de abordar o tema, seguindo as orientações da OMS.

Para Isabel Quental (2017), ao considerar o suicídio como problema de saúde pública e social, dá-se maior visibilidade ao mesmo, abrindo possibilidades para que todos possam contribuir para seu enfrentamento e solução. Pode-se observar que muitas ações têm sido realizadas, no entanto ainda persistem as dificuldades de prevenção e de protocolos para se lidar com a situação.

No entanto, o cumprimento dessas portarias vai além de uma imposição legal. Leis, portarias e recomendações não são efetivas se os profissionais que as executam não estiverem implicados na compreensão deste momento social em que estamos vivendo e no qual os jovens se encontram desamparados, carentes de vínculos e sem esperanças no futuro. Assim, para além dos aspectos legais que impõem aos profissionais e a toda a sociedade uma atenção especial ao fenômeno do suicídio, é fundamental estabelecer vínculos, importar-se efetivamente com o outro, escutar de forma aberta e sem julgamentos. Somente assim é possível garantir um trabalho efetivo.

\section{Considerações finais}

Neste artigo buscou-se discutir a questão do suicídio de adolescentes e jovens a partir de uma leitura da sociologia clínica, acrescida por leituras pós-modernas da realidade que estamos vivendo, considerando o sujeito como um ser social, influen- 
ciado pelo seu contexto. Assim, foram apresentados os principais suportes identitários disponíveis no momento para estes adolescentes e jovens, as altas expectativas que são lançadas sobre eles, as transformações nas relações e seu impacto na subjetividade e busca pelo sentido da vida. Também foram apresentados dados que mostram a comorbidade entre suicídio e outros transtornos mentais como depressão, ansiedade e uso de drogas

Os dados epidemiológicos apresentados assustam por sua magnitude, configurando a questão do suicídio como problema de saúde pública que necessita urgentemente de compreensão. Neste sentido, tanto a Organização Mundial de Saúde (OMS) como o Ministério da Saúde (MS) têm sugerido agendas para se discutir o tema dando a ele visibilidade. Leis, portarias e recomendações têm sido criadas. No entanto, o trabalho passa pelo envolvimento dos profissionais, das famílias e da sociedade com a questão. É preciso ações integradas nas diferentes esferas sociopsíquicas; é preciso coragem para se perguntar como somos afetados pelos sentimentos no nosso trabalho. Esta é uma pergunta necessária. Em tempos de pauperização dos vínculos, é fundamental resgatar o interesse e a preocupação com o outro.

Por fim, cabe relembrar que quando os jovens pensam em se matar, seu desejo maior é deixar de sofrer, acabar com algo que é intolerável e não com a sua própria vida. Surge, portanto, a necessidade de olhar atentamente para a sociedade paradoxal, consumista, exigente e pouco afetiva na qual estes jovens estão vivendo.

\section{Referências}

ANGERAMI, V. A. (Org.). A psicologia no hospital. 2. ed. São Paulo: Thomson Pioneira, 2013.

ANGERAMI-CAMON, V. A. Tendências em psicologia hospitalar. São Paulo: Thomson Pioneira, 2008.

ARAÚJO, L. da C.; VIEIRA, K. F. L.; COUTINHO, M. da P. de L. Ideação suicida na adolescência: um enfoque psicossociológico no contexto do ensino médio. Psico-USF, v. 15, n. 1, p. 47-57, Itatiba, 2010.

ASSUMPÇÃO JUNIOR, F. B. Suicídio na infância e na adolescência. In: ANGERAMI, V. A. (Org.). Sobre o suicídio: psicoterapia diante da autodestruição. Belo Horizonte: Artesã, 2018. 
BARRÓN, E. V.; KRMPOTIC, C. S. La prevención del suicídio juvenil: entre la enunciación y la acción. Revista Katálysis, v. 19, n. 1, p. 43-52, Florianópolis, Jun. 2016.

BARUS-MICHEL, J. O sujeito social. Belo Horizonte: Editora PUC Minas, 2004.

BAUMAN, Z. Vidas desperdiçadas. Rio de janeiro: Zahar, 2005.

. Modernidade líquida. Rio de Janeiro: Zahar, 2001.

BOTEGA, N. J. Comportamento suicida em números. Debates Psiquiatria Hoje, v. 2, n. 1, 2010.

BOTEGA, N. J. et alii. Prevalências de ideação, plano e tentativa de suicídio: um inquérito de base populacional em Campinas, São Paulo, Brasil. Cadernos de Saúde Pública, Rio de Janeiro, v. 25, n. 12, p. 2632-2638, Dez. 2009.

BRASIL. Presidência da República. Lei n. 13.819, de 26 de abril de 2019. Institui a política Nacional de Prevenção da Automutilação e do Suicídio. Diário Oficial da União, 29 Abr. 2019. Disponível em: <http://www.planalto.gov.br/ccivil_03/_ Ato2019-2022/2019/Lei/L13819.htm>. Acesso em: 20 Set. 2019.

—. Ministério da Saúde. Prevenção do suicídio: um manual para profissionais da saúde em atenção primária. Brasília: Ministério da Saúde, 2018. Disponível em: <http://www.portaldasaude/>. Acesso em: 17 Maio 2019.

— Ministério da Saúde. Plano Nacional de Prevenção do Suicídio. Programa Nacional para a Saúde Mental. Brasília: Ministério da Saúde, 2017. Disponível em: <http://www.portaldasaude.pt/NR/rdonlyres/>. Acesso em: 17 Maio 2019.

Ministério da Saúde. Agenda de ações estratégicas para a vigilância e prevenção do suicídio e promoção da saúde no Brasil, 2017 a 2020. Brasília, Ministério da Saúde, 2017. Disponível em: <https://www.neca.org.br/wp-content/uploads/ cartilha_agenda-estrategica-publicada.pdf>. Acesso em: 20 Set. 2019.

—. Ministério da Saúde. Portaria n.o 1.271, de 6 de junho de 2014. Define a lista nacional de notificação compulsória de doenças, agravos e eventos de saúde pública nos serviços de saúde públicos e privados em todo o território nacional, nos termos do anexo, e da outras providências. Diário Oficial da União, Seção 1, p. 68, 9 Jun. 2014. Disponível em: <http://bvsms.saude.gov.br/bvs/saudelegis/gm/2014/ prt1271_06_06_2014.html>. Acesso em: 20 Set. 2019. 
- Ministério da Saúde. Portaria n. 3.088, de 23 de dezembro de 2011. Institui a Rede de Atenção Psicossocial para pessoas com sofrimento ou transtorno mental e com necessidades decorrentes do uso de crack, álcool e outras drogas, no âmbito do Sistema Único de Saúde. Diário Oficial da União, Seção 1, p. 59, 30 Dez. 2011 (republicado no DOU n. 96, Seção 1, p. 37, 21 Maio 2013). Disponível em: <http://bvsms.saude.gov.br/bvs/saudelegis/gm/2011/prt3088_23_12_2011_rep. html>. Acesso em: 20 Set. 2019.

— Ministério da Saúde. Portaria n. 1.876, de 14 de agosto de 2006. Institui Diretrizes Nacionais para prevenção do suicídio a ser implantadas em todas as unidades federadas, respeitadas as competências das três esferas de gestão. Diário Oficial da União, Seção 1, p. 65, 15 Ago. 2006. Disponível em: <http://bvsms.saude. gov.br/bvs/saudelegis/gm/2006/prt1876_14_08_2006.html>. Acesso em: 20 Set. 2019.

CANTÃO, L.; BOTTI, N. C. L. Suicidal behavior among drug addicts. Revista Brasileira Enfermagem, v. 69, n. 2, p. 366-373, Brasília, Abr. 2016.

CARRETEIRO, T. C. O. C. A doença como projeto: uma contribuição à análise de formas de filiações e desafiliações sociais. In: SAWAIA, B. B. (Org.). As artimanhas da exclusão: análise psicossocial e ética da desigualdade social. 14. ed, p. 87-96. Petrópolis (RJ): Vozes, 2011.

_. Sofrimentos sociais em debate. Psicologia USP, v. 14, n. 3, p. 57-72, 2003.

— Exclusion sociale et construction de l'identité. Paris: Éditions l'Harmattan, 1993.

CASSEB, A. R. Adolescência e escolha profissional. In : GUIMARÃES, K. B. S. (Org). Saúde mental do médico e do estudante de medicina, v. 1, p. 25-40. São Paulo: Casa do Psicólogo, 2007.

CASTEL, R. Os marginais da história. Ser Social, v. 3, p. 55-66, 1998.

CHACHAMOVICH, E.; STEFANELLO, S.; BOTEGA, N.; TURECKI, G. Quais são os recentes achados clínicos sobre a associação entre depressão e suicídio? Brazilian Journal of Psychiatry, v. 31, Suplemento 1, p. S18-S25, São Paulo, 2009.

DURKHEIM, É. O suicídio: estudo de sociologia. São Paulo: Edipro, 2014.

FARO, A.; SANTOS, L. C. S. Suicídio na adolescência: panorama, cuidados e escuta. In: ANGERAMI, V. A. (Org.). Sobre o suicídio: psicoterapia diante da autodestruição, p. 169-189. Belo Horizonte: Artesã, 2018. 
GAULEJAC, V. de. O sujeito face à sua história: a démarche. "Romance familiar e trajetória social”. In: TAKEUTI M. N.; NIEWIADOMSKI, C. (Orgs.). Reinvenções do sujeito social: teorias e práticas bibliográficas, p. 61-73. Porto Alegre: Sulina, 2009.

— . Identidade. In: BARUS-MICHEL J.; ENRIQUEZ, E.; LEVY, A. (Orgs.). Dicionário de Psicossociologia. Lisboa: Climepsi, 2005.

GONÇALVES, A. M.; FREITAS, P. P. de; SEQUEIRA, C. A. da C. Comportamentos suicidários em estudantes do ensino superior: factores de risco e de proteção. Millenium, v. 40, p. 149-159, 2011.

GONÇALVES, B. Sobre o desespero. In: ANGERAMI, A. A. (Org.). Sobre o suicídio: a psicoterapia diante da autodestruição. Belo Horizonte: Artesã, 2018.

GONZÁLEZ-FORTEZA, C.; JUÁREZ LÓPEZ, C. E.; MONTEJO LEÓN, L.; OSEGUERA DÍAZ, G.; WAGNER ECHEAGARAY, F.; JIMÉNEZ TAPIA, A. Ideación suicida y su asociación con drogas, depresión e impulsividad en una muestra representativa de estudiantes de secundaria del estado de Campeche, México. Acta Universitaria, v. 25 (NE-2), p. 29-34. 2015.

HAROCHE, C. O sujeito diante da aceleração e da ilimitação contemporâneas. Educação e Pesquisa, v. 41, n. 4, p. 851-862, São Paulo, Out./Dez. 2015.

ISAAC SILVA, P. H. O que fazemos do que fazem de nós: trajetórias sociais e militância entre os catadores de materiais recicláveis no Brasil. Tese (Doutorado) - Departamento de Sociologia, Universidade de Brasília, Brasília, 2015.

KUTCHER, S.; CHEHIL, S. Suicide risk management: a manual for health professionals. Malden (MA): Blackwell, 2007.

MEDINA, A. M. E.; PÉREZ, G. R. E.; MEJÍA, Z. D. Prevalencia de depresión e ideación

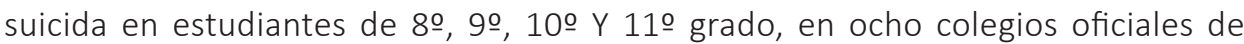
manizales. Hacia la Promoción de la Salud, v. 13, n. 1, p. 143-153, Manizales (CO), Dec. 2008.

MINUCHIN, S. Familias: funcionamento e tratamento. São Paulo: Artes Médicas, 1982.

MINUCHIN, S.; LEE, W.-Y.; SIMON, G. M. Dominando a terapia familiar. Porto Alegre: Artmed, 2008.

MORIN, E. Os sete saberes necessários à educação do futuro. São Paulo: Cortez, 2007. 
ORES, L. C. et alii. Risco de suicídio e comportamentos de risco à saúde em jovens de 18 a 24 anos: um estudo descritivo. Cadernos de Saúde Pública, v. 28, n. 2, p. 305-312, 2012.

ORGANIZAÇÃO MUNDIAL DA SAÚDE (OMS). Folha informativa sobre suicídio. Genebra: OMS, 2018.

—. Relatório sobre prevenção ao suicídio. Genebra: OMS, 2014.

_. Relatório mundial sobre violência e saúde. Genebra: OMS, 2002.

_. Prevenção do suicídio: um manual para profissionais da mídia. Genebra: OMS, 2000.

PENSO, M. A.; CONCEIÇÃO, M. I. G. Paradoxo do uso de drogas: da busca do prazer ao encontro com o sofrimento. In: ANGERAMI, V. A. (Org.). Sobre o suicídio: a psicoterapia diante da autodestruição. Belo Horizonte: Artesã, 2018.

PENSO, M. A. et alii. Jovens pedem socorro: o adolescente que praticou ato infracional e o adolescente que cometeu ofensa sexual. Brasília: Liber, 2012.

PEREIRA, M. A. D. O sofrimento psíquico na formação médica: percepções e enfrentamento do estresse por acadêmicos do curso de medicina. Tese (Doutorado) - Faculdade de Medicina, Universidade Federal do Goiás, Goiânia, 2014.

QUENTAL, I. A. Tentativas de suicídio: construindo dispositivos de prevenção um desafio para o SUS. 2017. Disponível em: <http://www.moreirajr.com.br/revistas. asp?fase =r003\&id_materia=4144>. Acesso em: 17 Maio 2019.

RHÉAUME, J. Relato de história de vida coletivo e empoderamento. In: TAKEUTI, N. (Org.). Reinvenções do sujeito social: teorias e práticas biográficas, p. 166-188. Porto Alegre: Sulina, 2009.

RIBEIRO, J. M.; MOREIRA, M. R. Uma abordagem sobre o suicídio de adolescentes e jovens no Brasil. Ciência \& Saúde Coletiva, v. 23, n. 9, p. 2821-2834, Rio de Janeiro, Set. 2018.

SANTOS, S. A.; LOVISI, G.; LEGAY, L.; ABELHA, L. Prevalência de transtornos mentais nas tentativas de suicídio em um hospital de emergência no Rio de Janeiro, Brasil. Cadernos de Saúde Pública, v. 25, n. 9, p. 2064-2074, Rio de Janeiro, Set. 2009.

SÉLOSSE, J. Adolescence, violences et déviances. Paris: Matrice, 1997. 
SENA, D.; PENSO, M. A. Por que nossos jovens se matam? In: ANGERAMI, V. A. (Org.). Suicídio e suas interfaces: o ardiloso emaranhado da autodestruição. Belo Horizonte: Artesã, 2019.

SENNETT, R. A corrosão do caráter: consequências pessoais do trabalho no novo capitalismo. Rio de Janeiro: Record, 2002.

SOLOMON, A. Um crime da solidão: reflexões sobre o suicídio. São Paulo: Companhia das Letras, 2018.

SOUZA, M. G. C. de; CASTRO, L. R. de. O projeto profissional de jovens das classes médias: orientações normativas e estratégias de inserção. Cadernos de Psicologia Social do Trabalho, v. 17, n. 2, p. 161-175, São Paulo, Dez. 2014.

TAKEUTI, N. M. No outro lado do espelho: a fratura social e as pulsões juvenis. Rio de Janeiro: Relume Dumará, 2002.

TEIXEIRA-FILHO, F. S.; RONDINI, C. A. Ideações e tentativas de suicídio em adolescentes com práticas sexuais hétero e homoeróticas. Saúde e Sociedade, v. 21, n. 3, p. 651-667, São Paulo, Set. 2012.

TORO-TOBAR R. A.; GRAJALES-GIRALDO F. L.; SARMIENTO-LÓPEZ J. C. Riesgo suicida según la tríada cognitiva negativa, ideación, desesperanza y depresión. Aquichan, v. 16, n. 4, p. 473-486, Bogotá, Oct. 2016.

XIBERRÁS, M. A sociedade intoxicada. Lisboa: Instituto Piaget, 1989. 
